\title{
Perceptions of Plagiarism in Academic Settings: Are University Students and Professors in the same Boat?
}

\author{
Roya Khoii, Mahsa Atefi \\ Islamic Azad University \\ Tehran North Branch, Iran
}

\begin{abstract}
Plagiarism has recently turned into a major concern for academics and academic institutions. Nevertheless, the reasons behind it continue to be obscure. Available statistical findings do not provide a very clear picture of the scale and nature of plagiarism; neither do they clarify the extent to which this phenomenon is changing through time or is different from country to country, from subject to subject, or among undergraduate and graduate students. Accordingly, the present study was carried out to investigate EFL University professors' and students' perceptions of the nature and causes of plagiarism. The participants consisted of $20 \mathrm{EFL}$ university professors and 40 university students studying TEFL at MA and PhD levels. Their responses to a 30-item Likert-Scale questionnaire demonstrated that both groups were equally aware of the nature of plagiarism and the related ethical issues, while the students had considerably different standpoints regarding the excuses and punishments for plagiarism.
\end{abstract}

\section{Introduction}

During the past few decades, practitioners in academic fields have been witness to frequent cases of plagiarism in academic settings, which has given rise to great concern regarding transgressive intercontextuality. Raising awareness about and taking preventative measures against academic transgression and scientific misconduct have always been a priority in academic and scientific circles; however, plagiarism still frequently takes place.

Plagiarism originates in the Latin word plagiarius, which means the theft of words as well as slaves [1]. It is defined as the illegal use of another's work, ideas, methods, or words without citing the original author. While a large body of research on the subject has focused on plagiarism in English-speaking contexts, cultural differences and specific features of L2 academic writing in ESL contexts have been recognized as contributing factors to plagiarism in non-English speaking settings as well [2]. Moreover, the rapid development of modern technologies has provided writers with unlimited access to a large body of textual resources, thus turning plagiarism into a huge problem snowballing at an alarming rate, particularly within academic contexts.

A growing body of literature demonstrates that plagiarism is perceived differently in various cultures due to deeper values that differ among Eastern and Western societies [3]. For example, it is claimed that in Asian societies memorizing and word-for-word copying are considered valued methods of learning [4], while paraphrasing is seen as changing the truth [5]. Perceptions towards plagiarism are so different in Eastern academic societies such that knowledge is believed to belong to all, and what authors say is accepted as fact and, thus, critical treatment of sources is seen as a disrespectful strategy and behavior [6]. Nevertheless, solely focusing on cultural differences as the main factor leading to plagiarism could be greatly misleading [7].

Furthermore, plagiarism in the context of education in a foreign language is a harder problem to study. Some attribute this to insufficient language and general study skills in foreign language studies programs and argue that non-English speaking writers' lack of sufficient proficiency in English academic writing should not stop them from expressing their views while borrowing others' words. Considering the scarcity of research in this field in Iran, the present study sought to shed some light on EFL learners' and teachers' perceptions of the nature and causes of plagiarism in Iranian academic communities.

\section{Literature Review}

Plagiarism has been defined as "the presentation of another's words or ideas as your own" [8]. Howard [9] identifies four types of plagiarism; (1) submission of someone else's written work as one's own, (2) patchwriting or blending others' sentences with one's own, (3) not citing the sources, and (5) not using quotations while using direct quotes. The second type, patchwriting, is the hardest to prevent as the presentation of the plagiarized work can occur in an alternate scientific community [2]. Howard [1] defines patchwriting as "copying from a source text and then deleting some words, altering grammatical structures, or plugging in one-for-one synonymsubstitutes." Nevertheless, she adds that some researchers describe patchwriting as a pedagogical 
opportunity and not a juridical problem. They believe that teachers should treat it as an important transitional strategy in the student's progress toward membership in a discourse community [1].

A major source for plagiarism is the internet, the content of which is often perceived by students to belong to the public and, thus, not in need of being acknowledged. While Freedman [10] sees the internet as a critical contributor to the rise of plagiarism, DeVoss and Rosati [11] assert that merely blaming the internet is a "failure to recognize and reward originality." Furthermore, some researchers distinguish between intentional and unintentional plagiarism.

It is also necessary to emphasize that there is a growing consensus of opinion that plagiarism should be studied as a cross-cultural phenomenon [3]. In other words, researchers need to recognize the hidden influence of culture and contextual factors on the self of the author in explicitly stating that they are using the words of someone else. Pennycock [12] argues that plagiarism is culturally conditioned and, as a result, differently interpreted in different cultures. He emphasizes that concepts of ownership, authorship and intellectual property, as developed in the Western context, enjoy their distinctive cultural and historical specifications. Hence, one can never expect all writers in all corners of the world and brought up within different cultures share Westerners' understanding of such terms.

The subject of plagiarism, in general, and the perceptions of students and the faculty towards it, in particular, have been widely studied. McCabe [13] conducted an extensive study on the perceptions of over 90,000 participants, including students and teachers, in American and Canadian universities. He reported a low acceptance of paper-based plagiarism, while observing a serious stance against copy-andpaste plagiarism using the internet among the participants. Following a survey of US college student's perceptions, Fish and Hura [14] found that the participants thought that other students were more likely to commit plagiarism than they were. They also reported that there were some types of plagiarism thought to be more serious than others; suggesting that the sharing of punitive consequences of plagiarism with students could lead to an elevated level of awareness.

On the other hand, Pritchett [15] compared the perceptions of undergraduate students and faculty members; reporting no significant difference among them, while observing a significant difference between male and female members of the faculty. She demonstrated that faculty members generally regarded plagiarism as a serious offence more than the students. The researcher concluded that, because the university policy may not provide sufficient penalties for plagiaristic infractions, the students do not consider it as wrongdoing. In the same vein, Roig [16] investigated professors' ability to detect plagiarism in students' paraphrased texts. He reported that even experts may make errors distinguishing plagiarism. The results of a similar study [17] exploring university instructors' perceptions of student self-plagiarism revealed that instructors did not really have a clear understanding of the issue.

In a Canadian study, Abasi and Graves [18] interviewed international graduate students and disciplinary professors to investigate the role of student-professor relationship dynamics on student text production. They concluded that it is ultimately the graduate students' responsibility to develop practical research skills and to learn to abide by plagiarism policies. A similar Australian study [19] examined Indonesian international students' understanding of plagiarism, reporting that for the majority of the participants the concept was a "completely unknown" and foreign notion. Two other Australian studies [20] demonstrated that providing students with in-class and online training modules on the subject led to significantly lower levels of plagiarism.

While $\mathrm{Hu}$ [21] reported that, not only in China but also in Italy, patch-writing is encouraged among students of disciplines such as history and science, Rinnert and Kobayashi [22] showed that Japanese students across a variety of disciplines lack proper training on plagiarism and authorship. Moreover, a Hungarian study [23] conducted interviews across universities and identified systematic corruption and lack of academic oversight as contributors to widespread plagiarism. Regarding the use of antiplagiarism software, Belter and du Pré [24] reported significant decreases in student plagiarism after the introduction of such software into the grading process.

In a case study in Australia [25], the researchers investigated the attitudes and abilities of 13 ESL students who were caught plagiarizing in a postgraduate engineering course at the University of Western Australia and were permitted to resubmit their assignments after participating in a compulsory workshop on writing skills. All the students were from non-English backgrounds. In their defense, the students stated that their misconduct was based on educational cultural ignorance of the university's expectations regarding plagiarism [25]. The findings of the study showed that, after attending the workshop, the participants did appear to possess the necessary skills to successfully avoid plagiarism. The students argued that the universities from which they had obtained their undergraduate degrees had not instilled in them the necessity of avoiding borrowing others' words and had not prepared them adequately in this regard.

There are also several notable studies of plagiarism among Iranian students in an eastern context. The findings of a study exploring the perceptions of faculty members towards plagiarism and self- 
plagiarism at a medical school in Tehran [26] indicate that there is a need for clear warnings against plagiarism in academic contexts and emphasize the necessity of using a plagiarism detection software as a solution to the related problems.

Another study at Isfahan Medical University [27] investigated the roots and consequences of academic cheating. Given the collected data, the researchers suggested that individual and communal factors are mainly responsible for student plagiarism. Furthermore, a study of the motives behind academic dishonesty in Iran [28] identified the following as the major culprits: (1) credentialism, (2) preferring quantity over quality in academic writing, and (3) lack of preventative measures.

Mahdavi-Zafarghandi, Khoshroo, and Barkat [29] conducted an extensive study on nearly 500 EFL master's students in 28 universities across Iran using a Persian questionnaire. They found that plagiarism was quite prevalent among the participants, and that their perceptions about the seriousness of plagiarism predicted their rates of plagiarism. Alternatively, Sabbaghan [30] studied nearly 100 under-graduate and graduate TEFL students in three branches of the same University. The participants were asked to compare pairs of passages and rate them based on the level of plagiarism involved. The researcher reported that, while the participants discerned direct copying as plagiarism, they tolerated paraphrased statements.

Given the differences among the findings of the studies conducted in various countries in the world, the present research was carried out to provide additional data on university professors' and students' view of the nature of plagiarism as well as the reasons behind committing it.

\section{Method}

The research question and a brief account of the instruments, participants, design, and procedure of the study are provided in this section.

\subsection{Research Question}

The present study was an attempt to find an appropriate response to the following question:

Q: What are EFL college professors' and students' perceptions of the nature and causes of plagiarism?

\subsection{Participants}

Twenty EFL university professors and 40 Iranian MA and $\mathrm{PhD}$ students in the field of TEFL participated in the study. The participants were both male and female with the majority being female. They were selected randomly from different classes at
North Tehran Branch of Islamic Azad University in Iran. The target population was too large to be studied in its entirety and, thus, a relatively small sample was chosen to fulfill the purpose of the study. It is necessary to emphasize that the initial sample consisted of about 40 professors and 100 students. However, when they learnt about the focus of the study, they either decided not to participate in the study or did not return the questionnaires.

\subsection{Instruments}

The main instrument used in this study was a 30item questionnaire in English which was developed by the researchers. One of the factors that prompted them not to use the already existing questionnaires was to avoid cultural clashes. Some of them included irrelevant questions (given the specific features of the ESL context in Iran), and some of them were extremely culture-bound. Of course, it is emphasized that the researchers adopted and adapted some of the questions in the previously used questionnaires while adding their own questions to the final instrument. The questions addressed the nature and concept of plagiarism as well as the reasons behind it. The number of items was deliberately limited to 30 to guarantee a greater return. The questions consisted of some statements which the participants agreed or disagreed with on a Likert-scale basis. Each statement was followed by five choices, as follows: (1) Strongly Disagree ( $\mathrm{SD}=1)$, (2) Disagree ( $\mathrm{D}=2)$, (3) Neutral (NS=3), (4) Agree (A=4), and (5) Strongly Agree $(\mathrm{SA}=5)$. The Cronbach's Alpha reliability of the questionnaire is given in Table 1 .

Table 1. Questionnaire Reliability

\begin{tabular}{|c|c|c|}
\hline Categories & $\begin{array}{c}\text { Cronbach's } \\
\text { Alpha }\end{array}$ & N of Items \\
\hline Total & .847 & 30 \\
\hline
\end{tabular}

\subsection{Procedure}

Firstly, the participants, both the professors and the students, were chosen based on availability. Then the purposes and premises of the study were explained to them to help achieve unbiased results. Afterwards, they were asked to fill out the plagiarism questionnaire. The researchers themselves closely monitored the process. The participants were assured about the confidentiality of their data. In spite of all the precautions taken by the researchers, almost half of the participants refrained from completing the questionnaire after seeing the questions.

When processing the results, the questions on the questionnaire were grouped into four categories, as follows: (1) knowledge of the concept of plagiarism, (2) excuses for justification of plagiarism, (3) 
punishments for plagiarism, and (4) academic ethics. Then the related scores and percentages were computed for each category, as well as for the total items on the questionnaire, and finally a number of independent samples t-tests were run to check the significance of differences between the means of the students' and professors' scores in relation to each category and on the total questionnaire.

\section{Results}

After scoring the two groups' responses to the questionnaire, the percentages of their responses to each category were calculated. Table 2 and 3 show both the total and average percentage scores per question category for professors and students, respectively.

Table 2. Professors' Percentage Scores

\begin{tabular}{|c|c|c|c|c|c|}
\hline & $\begin{array}{c}\text { Knowledg } \\
\mathrm{e}\end{array}$ & $\begin{array}{c}\text { Excuse } \\
\mathrm{s}\end{array}$ & $\begin{array}{c}\text { Punishmen } \\
\mathrm{t}\end{array}$ & $\begin{array}{c}\text { Ethic } \\
\mathrm{s}\end{array}$ & $\begin{array}{c}\text { Total } \\
\%\end{array}$ \\
\hline $\begin{array}{c}\text { Tota } \\
1\end{array}$ & 67.08 & 75.83 & 76.88 & 74.06 & 73.7 \\
\hline
\end{tabular}

Contrary to the researchers' initial assumptions, as Table 2 shows, the professors did not show a profound understanding of all aspects of plagiarism. In terms of the four categories, they obtained a uniform score across the board. On the other hand, the students displayed somewhat of a little higher than average percentage for each category. While on average, they scored higher on the academic ethics issues, they particularly scored lower regarding distinguishing the illegitimacy of excuses for committing plagiarism.

Table 3. Students' Percentage Scores

\begin{tabular}{|c|c|c|c|c|c|}
\hline & $\begin{array}{c}\text { Knowledg } \\
\mathrm{e}\end{array}$ & $\begin{array}{c}\text { Excuse } \\
\mathrm{s}\end{array}$ & $\begin{array}{c}\text { Punishmen } \\
\mathrm{t}\end{array}$ & $\begin{array}{c}\text { Ethic } \\
\mathrm{s}\end{array}$ & $\begin{array}{c}\text { Total } \\
\%\end{array}$ \\
& $\%$ & $\%$ & $\%$ & \\
\hline $\begin{array}{c}\text { Tota } \\
1\end{array}$ & 63.33 & 58.75 & 61.88 & 70.63 & 63.3 \\
\end{tabular}

Comparing the results in the two tables, it can be observed that the students' scores closely followed those of the professors in relation to the category of knowledge and ethics, while they were considerably lower regarding dismissing excuses and adopting proper punishment.

Figure 1 displays the descriptive statistics for the professors' and students' data. The results indicate that the professors obtained higher mean scores than the students on all the sub-scales of the questionnaire; ethics $(M=2.90$ vs. $M=2.88)$, excuses $(M=3.09$ vs. $M=2.31)$, knowledge $(M=2.72$ vs. $M=2.54)$ and punishments $(M=3.08$ vs. $M=2.49)$. Clearly, their total mean score $(\mathrm{M}=2.95)$ was also higher than that of students $(\mathrm{M}=2.53)$.

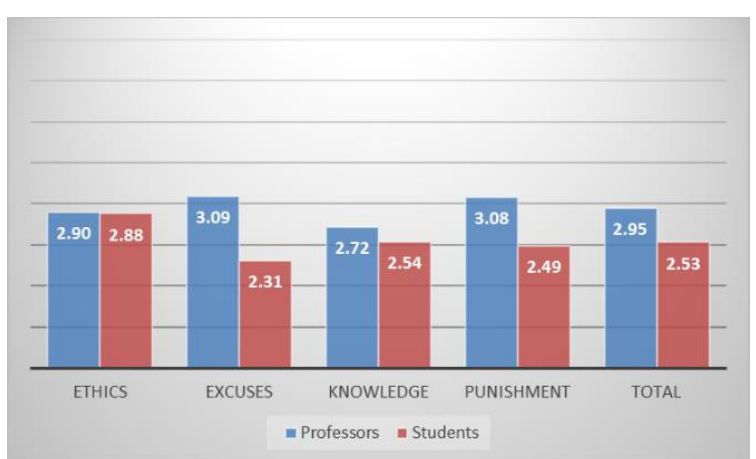

Figure 1. Means per Category for both groups

Later, after ensuring the normality of the two groups' score distributions, four independent samples t-tests were run in order to explore the significance of the differences between the mean scores of the two groups in each category. The results indicated that there were no significant differences between the mean scores of the two groups in the categories of ethics and knowledge of plagiarism $(\mathrm{df}=58, \mathrm{p}>.05)$. However, given the obtained $\mathrm{p}$ values $(\mathrm{df}=58, \mathrm{p}>.05)$ for the other two categories, it was decided that there were statistically significant differences between the professors' and students' attitude towards excuses for plagiarism and the potential punishment required, with the former group outperforming the latter.

Finally, another independent samples t-test was run to compare the professors' and students' total mean scores on the questionnaire. With $\mathrm{t}(58)=3.38$, $\mathrm{p}<.05,95 \%$ CI $[.170, .662]$, Cohen's $\mathrm{d}=.939$ representing a large effect size), it was concluded that the professors had obtained a significantly higher total mean score, indicating that they had a relatively deeper perception of the concept of plagiarism.

\section{Conclusions and Discussion}

The results of this study confirm what other researchers have reported in similar studies in both EFL Eastern and non-Eastern contexts in that both professors and students seem to lack sufficient understanding of the nature of plagiarism and the ways to avoid it. In part, one can explain the findings by attributing them to the Eastern values of knowledge preservation and dissemination. However, as others have indicated, mere cultural roots cannot account for such results. The students' lower scores could be due to the fact that even the professors who teach them do not have a solid knowledge of plagiarism, which naturally leads to their students' lack of sufficient knowledge in this regard. The professors' less than perfect perceptions of plagiarism might have stemmed from lack of training, contextual disincentives, and a general departure from taking the issue seriously in an environment where their cohorts show little to no effort in doing the same. 
Undoubtedly, this is a serious situation, which demands an appropriate and prompt remedy.

As illustrated previously, both groups held similar attitudes towards ethical considerations and had relatively equal perceptions of the nature of plagiarism. Nevertheless, knowing about the nature of some phenomenon and being aware of what is ethical about it are not enough. In spite of their agreement in relation to these two issues, the students did not seem to follow their professors when it came to justifying their potential attempts at plagiarism and the punishment that could follow. The students believed that when the professors do not provide them with a solid understanding of plagiarism, they should not adopt a punitive attitude towards them. In fact, the researchers find the professors' high percentage regarding punishment for borrowing others' words quite surprising.

Being aware of their own negligence regarding the clarification of the concept of plagiarism and preparing the students to create original works, the professors seemed to be lenient when it came to accepting excuses for committing intertextual transgression. However, the students did not seem to strongly believe that bringing excuses is acceptable for committing misconduct.

One step in helping the issue is to develop policies in academic settings that require taking serious disciplinary actions against violators of academic codes of conduct. These policies might presently exist on paper, but they are rarely exercised fully and practically. Another positive measure to take is to organize events, workshops, and training courses and opportunities, first and foremost, for professors and then for students. Alternatively, requiring students to take a course on the issue in their first year can help them avoid plagiaristic mistakes further down the line. Finally, the researchers believe that the increasing adoption of text-matching software in academic settings could prevent the occurrence of plagiarism to a large extent. Undoubtedly, the students should be familiarized with the nature and functions of such software before they are put into use in related contexts. All in all, it seems that the adoption of an educative approach to plagiarism would be more constructive than a punitive one in academic contexts.

\section{References}

[1] R. M. Howard, "Plagiarism, Authorships and the Academic Death Penalty", College English 57 (7), 1995, 788-806.

[2] D. Pecorari and B. Petrić, "Plagiarism in SecondLanguage Writing", Language Teaching, vol. 47, no. 3, 2014, pp. 269-302.

[3] J. Hall, "Plagiarism Across the Curriculum: How Academic Communities Can Meet the Challenge of the
Undocumented Writer", Across the Disciplines, vol. 2, no. 9, 2005.

[4] Q. Gu and J. Brooks, "Beyond the Accusation of Plagiarism", System, vol. 36, no. 3, 2008, pp. 337-352.

[5] N. Hayes and L. D. Introna, "Cultural Values, Plagiarism, and Fairness: When Plagiarism Gets in the Way of Learning", Ethics and Behavior, vol. 15, no. 3, 2005, p. 213-231.

[6] D. Pecorari, "Good and original: Plagiarism and Patchwriting in Academic Second-Language Writing", Journal of Second Language Writing, vol. 12, 2003, p. $317-$ 345 .

[7] F. Hyland, "Dealing with Plagiarism when Giving Feedback", ELT Journal, vol. 55, no. 4, 2001, pp. 375-381.

[8] E. Babbie, "Plagiarism", available at https://gatech.instructure.com/courses/18811/files/581853/ download?download...1, accessed 20 May 2019.

[9] R. M. Howard, "A Plagiarism Pentimento", Journal of Teaching Writing, 1993, pp. 233-245.

[10] M. Freedman, "Don't Blame the Internet for Plagiarism", Education Week, vol. 18, no. 14, 1998, pp. 3640.

[11] D. DeVoss and A. C. Rosati, "'It Wasn't me, Was it?" Plagiarism and the Web", Computers and Composition, vol. 19, no. 2, 2002, pp. 191-203.

[12] A. Pennycook, "Borrowing Others' Words: Text, Ownership, Memory, and Plagiarism", TESOl Quarterly 30 (2), 1996, 201-230.

[13] D. L. McCabe, "Cheating among College and University Students: A North American Perspective", International Journal for Educational Integrity, vol. 1, no. $1,2005$.

[14] R. Fish and G. Hura, "Students' Perceptions of Plagiarism", Journal of the Scholarship of Teaching and Learning, vol. 13, no. 5, 2013, pp. 33-45.

[15] Pritchett, S., Perceptions about Plagiarism between Faculty and Undergraduate Students, Doctoral dissertation, San Diego: Alliant International University, 2010.

[16] M. Roig, "Plagiarism and Paraphrasing Criteria of College and University Professors", Ethics \& Behavior, vol. 11 , no. 3, 2001, pp. 307-323.

[17] C. Halupa and D. U. Bolliger, "Faculty Perceptions of Student Self-Plagiarism: An Exploratory Multi-University Study", Journal of Academic Ethics, vol. 11, no. 4, 2013, pp. 297-310.

[18] A. R. Abasi and B. Graves, "Academic Literacy and Plagiarism: Conversations with International Graduate Students and Disciplinary Professors", Journal of English for Academic Purposes, vol. 7, no. 4, 2008, pp. 221-233. 
[19] S. Kutieleh and T. S. Adiningrum, "How Different Are We? Understanding and Managing Plagiarism between East and West", Journal of Academic Language and Learning, vol. 5, no. 2, 2011, pp. A88-A98.

[20] C. Owens and F. A. White, "A 5-Year Systematic Strategy to Reduce Plagiarism among Year Psychology University Students", Australian Journal of Psychology, vol. 65 , no. 1, 2013, pp. 14-21.

[21] J. Hu, "An Alternative Perspective of Language ReUse: Insights from Textual and Learning Theories and L2 Academic Writing", English Quarterly Canada, vol. 33, no. 1-2, 2001, p. 52.

[22] C. Rinnert and H. Kobayashi, "Borrowing Words and Ideas: Insights from Japanese L1 Writers", Journal of Asian Pacific Communication, vol. 15, no. 1, 2005, pp. 15-29.

[23] J. Horváth, ""The Professional Community Needs to Know about these Issues": Plagiarism in Hungarian Universities", School of Culture (Iskolakultúra), vol. 22, no. 7, 2012, p. 96-110.

[24] R. W. Belter and A. du Pré, "A Strategy to Reduce Plagiarism in an Undergraduate Course", Teaching of Psychology, vol. 36, no. 4, 2009, pp. 257-261.

[25] B. Stappenbelt, Ch. Rowles and E. May, "Cultural Influence on attitudes to Plagiarism", Teaching and Learning Forum, 2009.

[26] M. Ghajarzadeh, K. Hassanpour, S.-M. Fereshtehnejad, A. Jamali, S. Nedjat and K. Aramesh, "Attitude towards Plagiarism among Iranian Medical Students", Journal of Education and Practice, vol. 39, no. 4, 2013, p. 249.

[27] R. Aghajani, M. Keyvan Ara, M. Cheshmeh Sohrabi and A. Papi, "Pathological Analysis of Cheating and Scientific Theft: Based on a Qualitative Research", Iranian Journal of Education in Medical sciences/Special Issue on of Educational Development and Health Promotion, 2012, pp. 1063-1073.

[28] S. Darouian and M. Faghihi, "The Study of Motives and Causes of Plagiarism", Quarterly of the Missions of Public Management, vol. 1, 2012, pp. 137-154.

[29] A. Mahdavi-Zafarghandi, F. Khoshroo and B. Barkat, "An Investigation of Iranian EFL Masters Students' Perceptions of Plagiarism", International Journal of Education Integrity, vol. 8, no. 2, 2012, p. 69-85.

[30] S. Sabbaghan, "Iranian TEFL Students' Perception of Plagiarism", Journal of English Language Studies, vol. 1, no. 4,2010 , p. 23-40. 